\title{
COMPARISON ANALYSIS THE USE OF MODERN TECHNOLOGIES BY FIRE RESCUE SERVICE
}

\author{
Katerina Vichova, Martin Hromada, Jarmil Valasek \& Frantisek Paulus
}
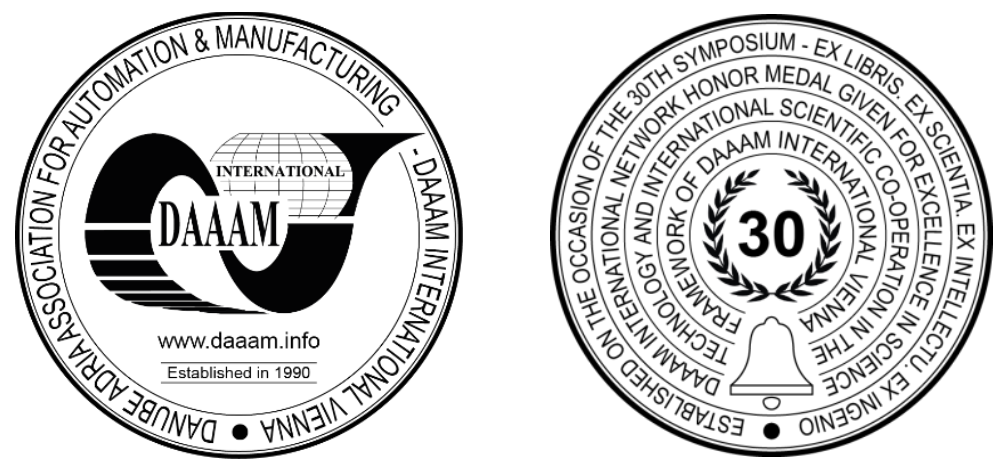

This Publication has to be referred as: Vichova, K[aterina]; Hromada, M[artin]; Valasek, J[armil] \& Paulus, F[rantisek] (2020). Comparison Analysis the Use of Modern Technologies by Fire Rescue Service, Proceedings of the 31st DAAAM International Symposium, pp.0535-0541, B. Katalinic (Ed.), Published by DAAAM International, ISBN 978-3-90273429-7, ISSN 1726-9679, Vienna, Austria

DOI: $10.2507 / 31$ st.daaam.proceedings.074

\begin{abstract}
In all areas of human life, we encounter modern technologies. These technologies represent a significant simplification of basic daily life and provide improvements in saving lives and health. One of the contemporary technologies should be a firefighting robot. This robot helps firefighters in hardly accessible places. These technologies can protect the life and health of firefighters and transport water to the scene, where it is not always possible or at high risk. The paper aims to present the current state of modern information technologies in the Czech Republic. Based on different experiences, measures will be proposed to increase the intervention's success by transporting the necessary fire equipment to the scene. The first part of the paper presented the current state of the situation and the literature review. The second part describes the methodology of the paper, where primarily was used the Pareto diagram. The central part of the paper is the results. In this part are presented the used modern technologies which are used by FRS. Next was used the Pareto analysis and evaluation based on the scale. Finally, the Pareto diagram showed, based on which we could take the information about FRS's preparedness for the selected disasters. The last part of the paper is the recommendation and verification, recommendations, and conclusion.
\end{abstract}

Keywords: Information Technologies; FRS; Robots; Remote Access; Emergency Management.

\section{Introduction}

Several disasters threaten all over the world. Climate change has been occurring globally. [1] Climate change has several impacts. One of them could be an impact covering disasters. Their number has risen sharply from about 200 per year to more than 400 per year in recent decades. [2] These situations pose significant challenges for the poorest and most vulnerable populations and disaster and emergency management leaders. [3] Next, disasters constitute sharp shocks to environmental and socioeconomics systems, entailing the loss of life and property. [4] These situations disturb the infrastructure of the affected territory. However, society is traditionally dependent on a whole range of infrastructures. [5] Over time, some of them - or some of their parts, which are of vital importance for society, began to be designated as Critical. [6] The terrorist attacks in September 2001 have changed the perception of critical infrastructure security. [7] Based on these, there are defined various sectors, for example, energy, food, healthcare, transport, financial services, and emergency services too. 
We could classify Joint Rescue System, radiation monitoring and forecasting, warning, and reporting service to the emergency services. [8] All of these services must work in a time of disaster. We could include Fire Rescue Service, Medical Rescue Service and Police of the Czech Republic to the Joint Rescue Service in the Czech Republic. The aim of this paper will be the focus of the Fire Rescue Service. The Fire Rescue Service of the Czech Republic performs tasks in the field of the Joint Rescue System. It provides, in particular, directing Joint Rescue System and preparing for emergencies, organizing the Czech Republic's involvement in international abroad emergency operations, and providing abroad humanitarian aid. The Fire Rescue Service coordinates the rescue and liquidation works, directs the process of emergency planning, prepares type plans for dealing with emergencies, fulfills tasks in the area of prevention of major accidents caused by selected dangerous substances; in the field of fire protection, civil emergency planning and in the field of population protection. [9] Fire Rescue Service uses several modern technologies. Dynamical development of technologies is a result of man's desire to achieve a higher living standard. [10] However, there is essentially the introduction of new technologies to increase the level of competence. For example, wildfires destroy thousands of hectares every summer all over the world. [11] For this situation, we could use modern technologies, such as drones [12], robots, and others. It is well recognized that profit-oriented organizations are more advanced than public organizations to absorb and implicate new technologies. [13]

Fire in the building represents a significant threat to the firefighters. There may be a few ceilings or roofs that could injure firefighters. With the help of modern means of transport, it is possible to avoid this threat. In particular, that means the use of robots to ensure firefighting at the scene without the firefighters.

The paper will be divided into several parts. Firstly, there will be a literature review and survey about modern (transport) technologies by the Fire Rescue Services in the Czech Republic. Secondly, there will be an analysis of preparedness for the selected emergencies. Finally, there will be a proposal for the new transport technologies for population protection at Fire Rescue Service activities. This proposal will be directed for the critical infrastructure protection and the Fire Rescue Service preparedness level optimization for the disasters.

The aim of the paper will be targeted to the research of new modern (transport) technologies for increasing the protection of the state and its citizens in the context of Fire Rescue Service activities. It will include urgent and long-term measures to protect the population. For this purpose, it will be used the Pareto analysis. Further research will be focused on introducing new technologies to save the lives of FRS in times of crisis.

\section{Methodology}

In this paper was used several methods. Firstly, there was used an analysis method. Based on the analysis, we could take the resume of the areas. Secondly, there was used as a comparative method. This method was used for the comparison of the results from the survey. There was analyzed the preparedness of the Fire Rescue Services for several emergencies. Next, there was used in the study. Based on the study, we take information about using modern technologies by Fire Rescue Services in the Czech Republic. And further for the analysis of preparedness of Fire Rescue Services for several emergencies.

Pareto's analysis is also used. This principle indicates that a small group of causes or phenomena is of fundamental importance, and a large group of causes and phenomena is of negligible significance. Based on this analysis, it is possible to determine which phenomena are significant for the organization, and it is necessary to pay attention to them. Conversely, aspects whose impact on an organization is negligible can be determined. It will save the organization's resources. The process of implementing the Pareto analysis involves elaborating a chart that appropriately captures critical and less critical phenomena and causes.

The Pareto analyses consist of the following steps:

1. Determination of the subject of analysis and list of examined categories.

2. Data Collection.

3. Arrangement and preparation of data for analysis.

4. Creating a Bar Graph.

5. Decisions on the following steps and their implementation.

After meeting points 1 - 4, a chart will be created, and a decision on the next steps could be made. The graph also includes a Lorenz curve that can help separate key and less critical phenomena. [14]

\section{Results}

This part will be divided into two parts. Firstly, there will be an analysis of the preparedness of Fire Rescue Services in the Czech Republic. The results will be presented based on the Pareto analysis. Secondly, there will be an analysis of modern technologies which are using in the Czech Republic. Based on this, studies will be presented in the next part (Discussion), which also proposed new technologies and FRS methods. The data was taken by the survey, which was sent to 396 respondents. We take feedback from the 151 respondents. The survey was sent to the members of the Fire Rescue Services in the Czech Republic. 


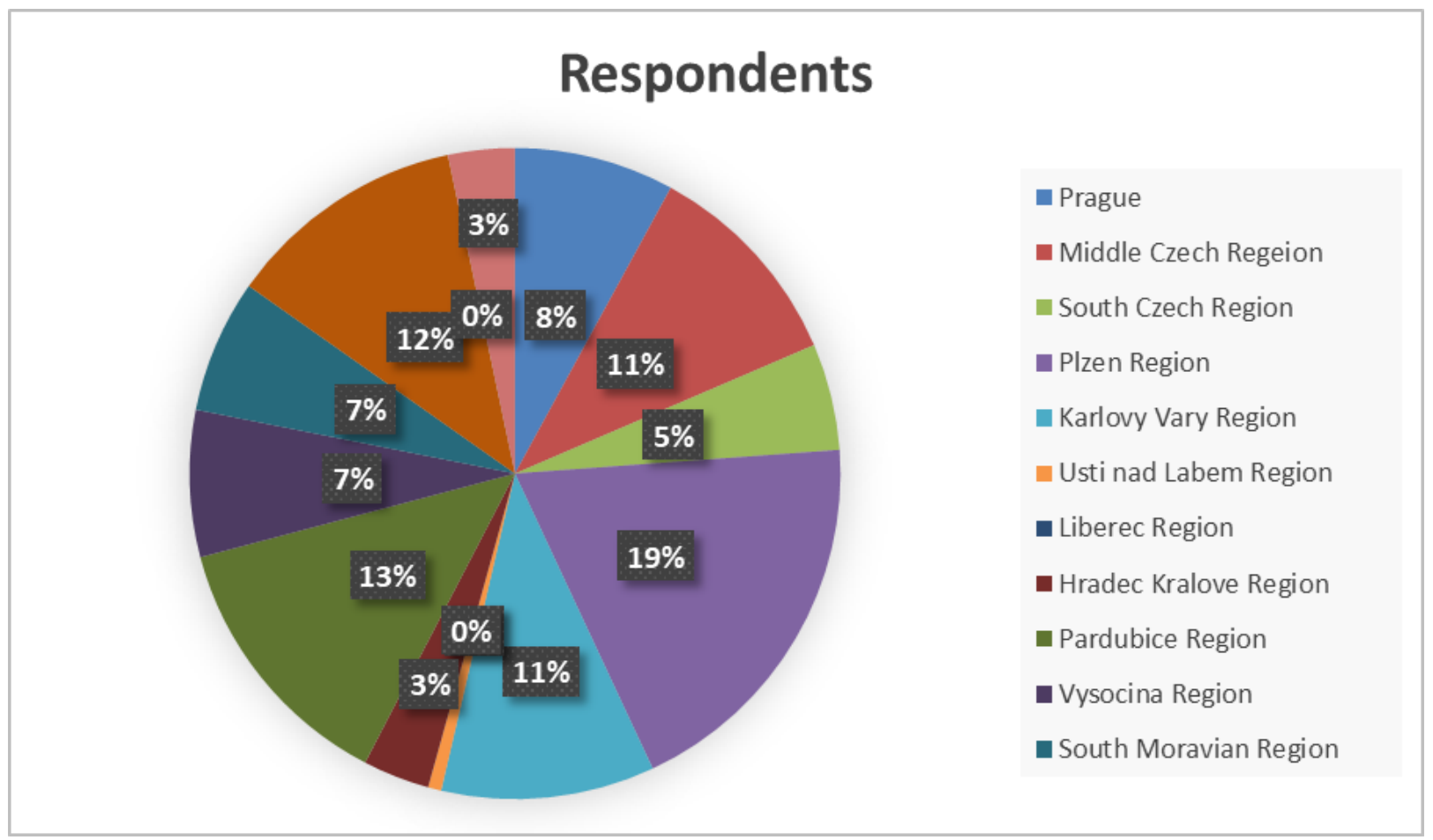

Fig. 1. The number of respondents

Figure 1 shows the number of respondents in the selected regions in the Czech Republic. As can be seen, the higher the number of feedback we take in the Plzen Region - a total of 29 respondents (19.2 percent). On the other hand, in the few regions, we take no answer. The first part of the survey was focused on using modern (transport) technologies during the interference by the Fire Rescue Service in the Czech Republic. There was a choice of five parameters (drones, robots, thermal cameras, and others). It was also possible to write notes.

\section{Modern technolgies}

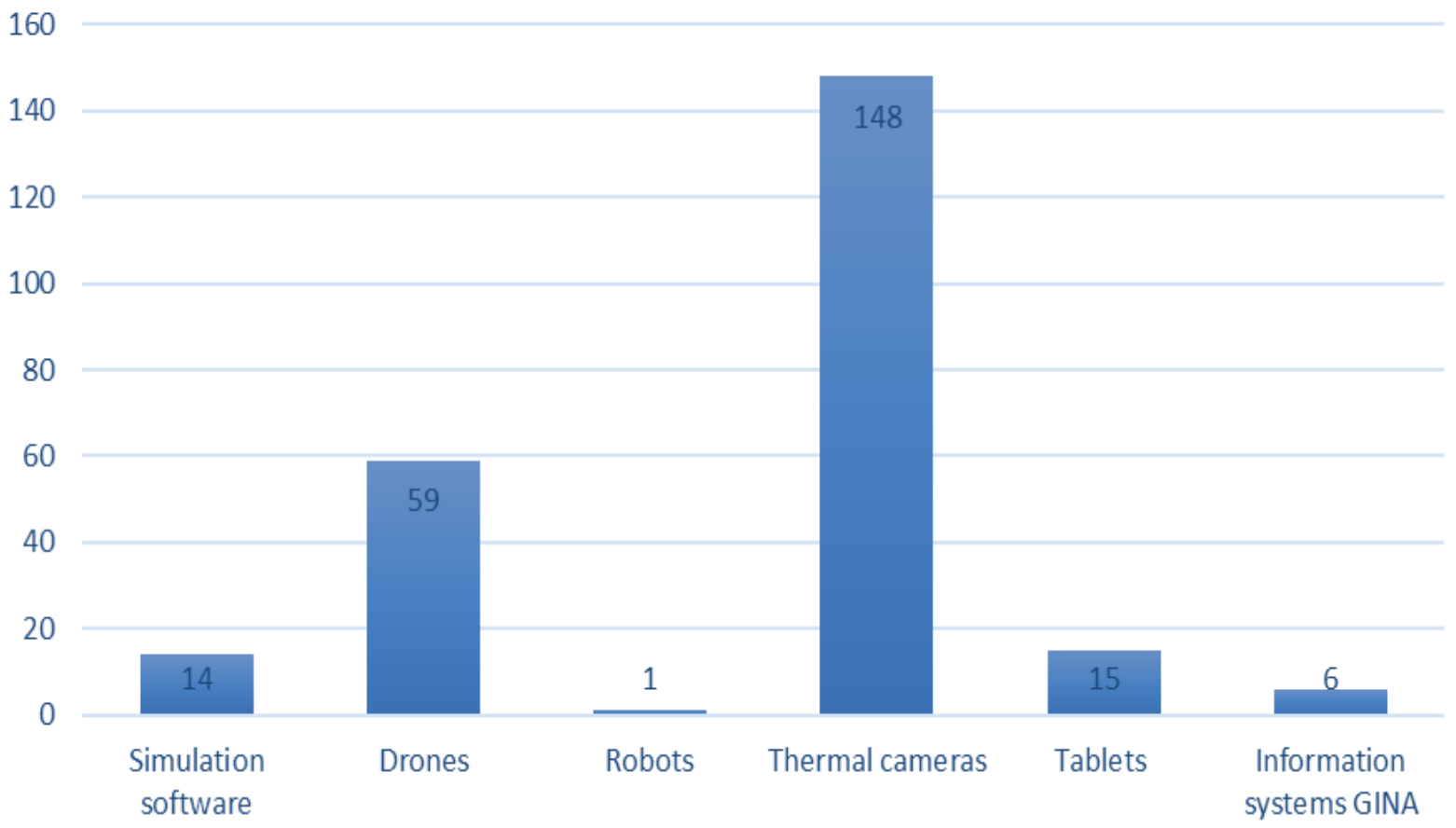

Fig. 2. The use of modern technologies by FRS 
Figure 2 shows the use of modern technologies by Fire Rescue Services in the Czech Republic. As can be seen, the respondents' central part states that they are using thermal cameras during the disaster. Next, we can see that 59 respondents say that they are using drones. It is quite a high number. Then, some of them are using tablets and the simulation software as Terex and others. On the other hand, we can see that only one respondent published that they are using robots during the interference. To the last, we can class Cobra water jet extinguishing, 3D laser scanning system, and others. The second part of the survey was focused on the Fire Rescue Service preparedness for different situations. The evaluation was on the scale of the preparedness 1 - 4 (see Table 1).

\begin{tabular}{|c|c|c|}
\hline Scale & Number expression & Verbal expression \\
\hline $\mathbf{4}$ & $100-75$ & Preparedness \\
\hline $\mathbf{3}$ & $74-50$ & Partially preparedness \\
\hline $\mathbf{2}$ & $49-25$ & Almost preparedness \\
\hline $\mathbf{1}$ & $24-1$ & Unpreparedness \\
\hline
\end{tabular}

Table 1. Scale

Based on the answers from the respondents and evaluation from table 1, we take the results.

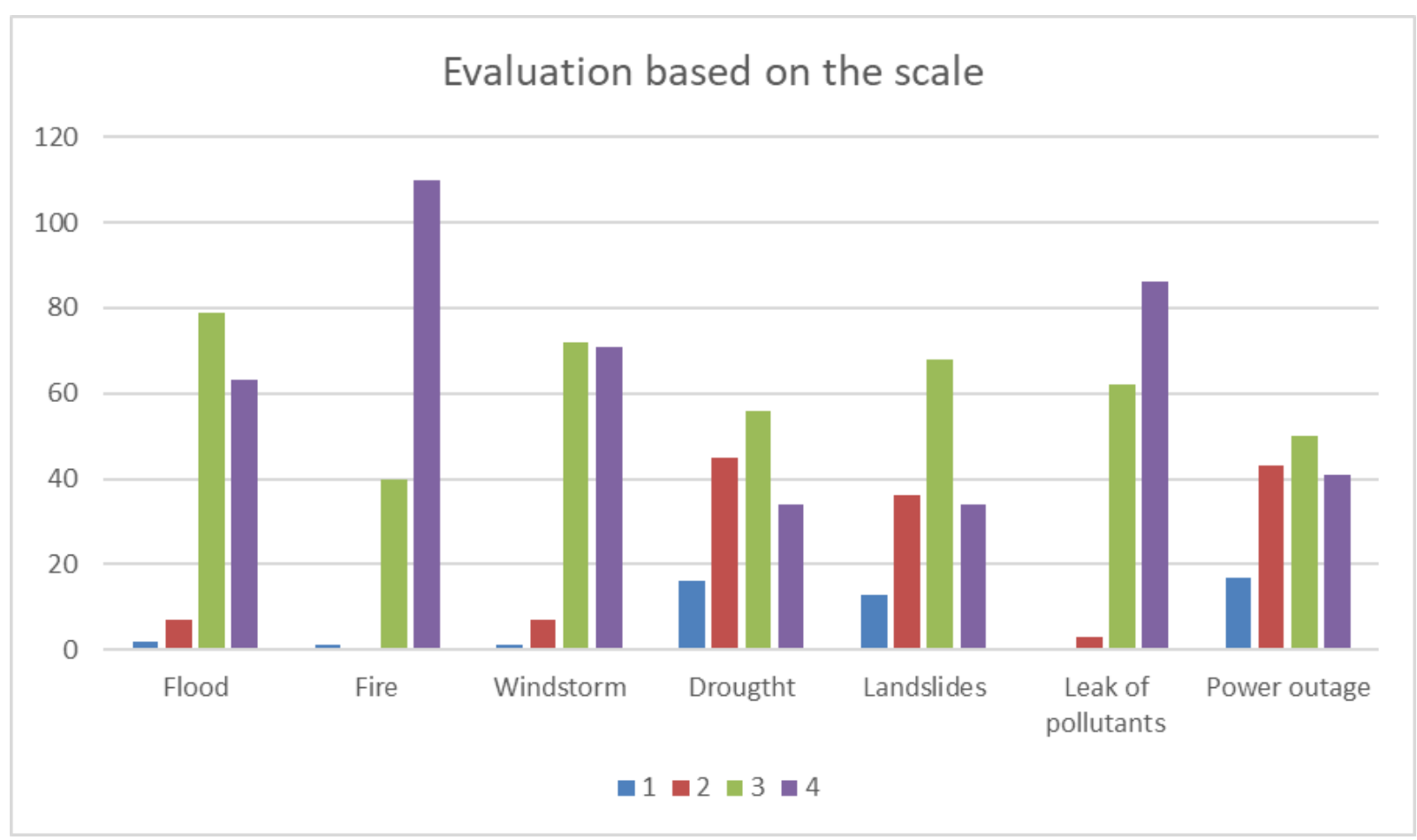

Fig. 3. Evaluation based on the scale

Figure 3 shows the evaluation based on the scale from table 1. There were analyzed seven situations and the preparedness of Fire Rescue Service for them. As can be seen, the best preparedness is related to the fire. The secondbest evaluation takes the leak of pollutants. On the other hand, the worst preparedness is for drought and power outage.

\begin{tabular}{|l|l|l|l|}
\hline Situation & Data & Cumulative Score & Cumulative \% Score \\
\hline Fire & 3.7 & 3.7 & $16.6 \%$ \\
\hline Leak of pollutants & 3.6 & 7.3 & $32.7 \%$ \\
\hline Wind storm & 3.4 & 10.7 & $48 \%$ \\
\hline Flood & 3.3 & 14 & $62.8 \%$ \\
\hline Landslides & 2.8 & 16.8 & $75.3 \%$ \\
\hline Power outage & 2.8 & 19.6 & $87.9 \%$ \\
\hline Drought & 2.7 & 22.3 & $100 \%$ \\
\hline
\end{tabular}

Table 2. Score based on the evaluation

Based on the evaluation by the Pareto analysis was created Figure 4. 


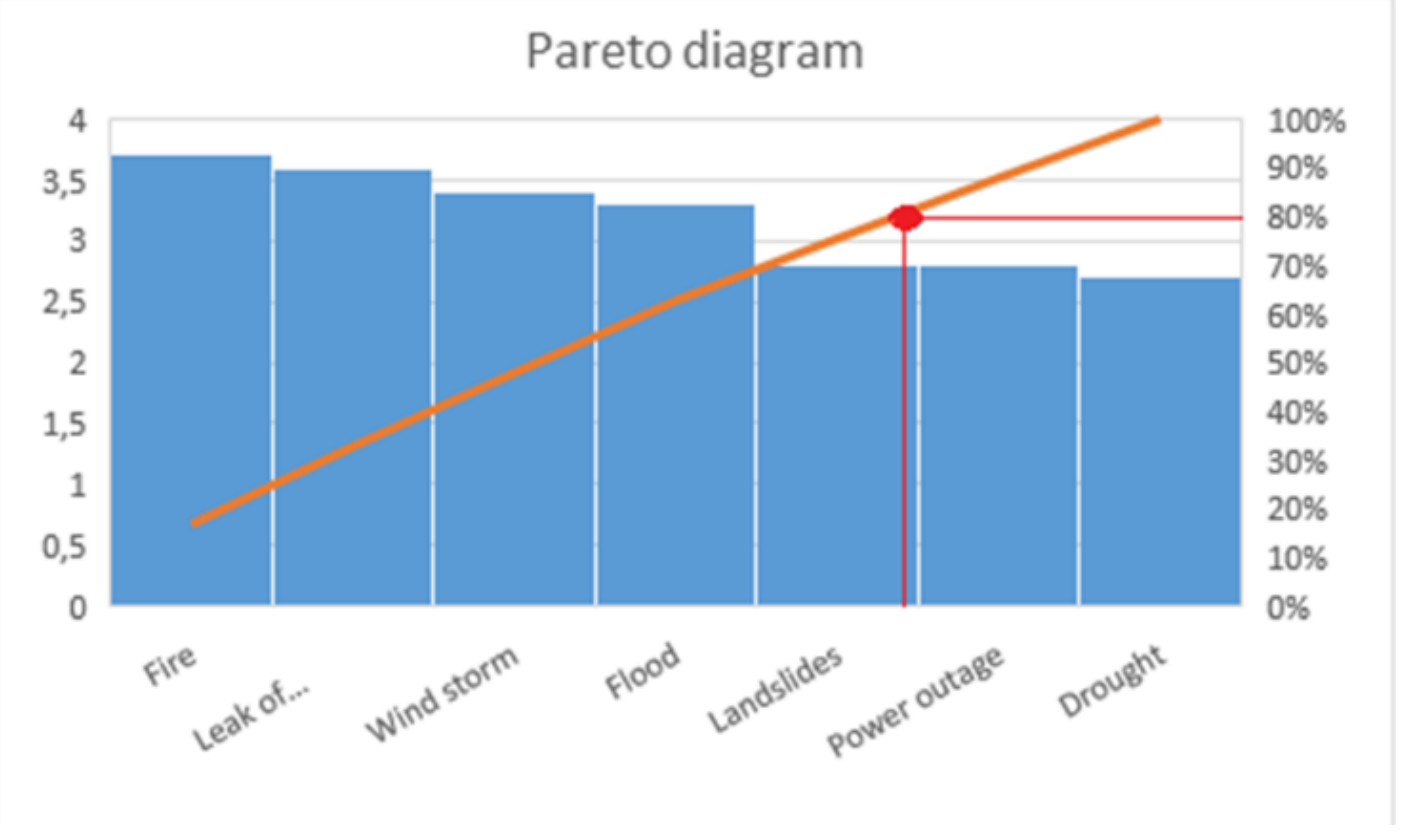

Fig. 4. Pareto diagram

Figure 4 shows the Pareto diagram from the Fire Rescue Service preparedness analysis in the context of modern technologies application. Based on the Pareto analysis, we take the information, for which situations are the Fire Rescue Services preparedness and for which not. The Lorenz curve determines disaster preparedness based on Table 1. As can be seen, the Fire Rescue Services in the Czech Republic are mostly prepared for the fire, leak of the pollutants, windstorm, flood, and landslides as an additional value of modern technologies application. On the other hand, the Fire Rescue Services are not so prepared for the power outage and drought. Even though the landslide and power outage situations have the same data, they are divided differently based on Pareto analysis. It is due to the cumulative score.

\section{Discussion}

The paper's aim was targeted to the research of new modern information technologies application for increasing the protection of the state and its inhabitants in the context of Fire Rescue Service activities. Based on the literature review, we could proclaim that the number of disasters increased based on climate change. These disasters have a high impact on the life and health of inhabitants of the whole world. One of the paper aims was to analyze the preferences of modern technologies applied in the context of Fire Rescue Services activities' preparedness. Based on the survey, we take the study for which situations are the Fire Rescue Services prepared well and not. Based on the results, we take the result that they are highly prepared for the fires. On the other hand, and as we declared in the first part, the use of modern information technologies by the Fire Rescue Services was analyzed. Based on the survey, we take the results about using technologies; however, they do not use technologies where no human intervention is required but could be replaced by a machine (robots, drones). The same situation is in the use of information systems during the emergency. Information systems have become an essential part of crisis management. [15]

In this part, we would like to recommend increasing using drones by the Fire Rescue Services. The drones could be utilized by numerous situations, such as drought and fires caused by it, flood, missing people in the field. Fire (detection, monitoring, mapping, extinguishing); flood (monitoring, mapping, comparison with the pre-defined flood area (Q100), transport of goods); leak of dangerous substance (monitoring, measurement, monitoring of leakage of hazardous materials into watercourses); traffic accidents (monitoring, mass accident in poorly accessible terrain, tunnel accident - tracking of the current state). [16]

The transmission of the image from the robot is transmitted using modern information technology, and the intervening persons use tablets to guide the robot to intervene. Introducing modern technologies by the Fire Rescue Services could increase the level of the rescued inhabitants, property, and of course, also environment. Interventions by FRS members are becoming increasingly complicated. Landfills can be covered with landslides, bushfires, and the site becomes difficult to reach for rescue services. Modern technologies, such as drones and robots, can be used for this purpose. The drone can be used to pre-examine the affected area. Conversely, a robot can be a way to get to the scene quickly. With the help of cameras, rescue services can monitor the current situation and assist.

In Australia, they use TAF 20 robots. High-tech equipment can move and move obstacles (cars) out of the way using a front bumper. It also has a built-in, highly efficient water cannon with a range of up to 90 meters. It is also equipped with an efficient fan that can blow smoke from buildings. [17] 
The same technologies are using in France. There was used robot for the massive fire of Notre Dame Cathedral. Colossus, a remote-controlled firefighting automaton designed and built by Shark Robotics, looks a bit like an army tank - if the tank were painted fire-engine red, retrofitted with a massive hose instead of a gun turret, and shrunk down to the size of a large dog. It can project water up to distances of 250 meters. [18] The disaster relief robot has the characteristics of a dangerous operation robot, which belongs to a branch of a dangerous operation robot and is a new development field of the robot. Under the system, instead of firefighters or rescuers, they enter the fire scene for investigation, real-time return the video images of the harsh environment. They can put out the fire, help the rescuers obtain accurate field information, minimize the loss of people's lives and property, and reduce the risk faced by firefighters. [19]

Based on the data we take in the survey, we take in information that the Czech Republic is not prepared for a robot's extinguishing. It represents the modern way of extinguishing the world. The firefighters have the feedback as the video, and the robot is watered for the fire trucker. The introduction of this technology would significantly reduce the risk of firefighters who have to search for collapsing buildings. Search and rescue robots must cover a wide range of application areas. [20]

\section{Conclusion}

The paper was divided into several parts. Firstly, there was an introduction to the area of disasters in the context of critical infrastructure. Secondly, there was a methodology introduced, where was used method of research presented. Thirdly, there was the central part of the paper - results. In this part, we offer the survey results in the area of using modern (transport) technologies by the Fire Rescue Services in the Czech Republic. As was mentioned, there is different equipment for advanced technologies at the fire brigade in individual regions. From all of the respondents said that only one is using the robot for the interference.

On the other hand, almost all use thermal cameras in times of emergency. And the second part of the results is in Fire Rescue Services preparedness for the selected emergencies. Based on the survey, we take the result that Fire Rescue Services are the most prepared for the fires in the context of modern technologies application. Next, there was an applied Pareto diagram. Based on this, we take results, for which situations are Fire Recuse Services in the Czech Republic well prepared. They are prepared for the fire, leak of pollutants, wind storms, floods, and landslides.

On the other hand, their weakness is the preparedness for emergencies such as power outage and drought. Drought is a new threat, and we need to start paying attention to this emergency. Finally, there was a discussion with the recommendation and proposals to introduce new technologies for the Fire Rescue Services. The shortcoming in the form of the missing number of firefighting robots that can get to the fire scene without the need to endanger the life and health of firefighters was emphasized.

\section{Acknowledgments}

This research was supported by the project VI20152020009 - Targeted Applied Research of New Modern Technologies, Methods and Procedures to Increase the Field of Fire CR - CAVHZS (2015-2020, MV0 / VI).

\section{References}

[1] Kim, T.-K.; Choi, S.-J.; Choi, J.-H.; Kim, J.-H. J. (2019). Prediction of Chloride Penetration Depth Rate and Diffusion Coefficient Rate of Concrete from Curing Condition Variations due to Climate Change Effect. International Journal of Concrete Structures and Materials. Vol. 13, No. 15, 2019, pp. 1-13, ISSN 1976-0485, DOI: 10.1186/s40069-019-0333-4.

[2] Luskova, M.; Leitner, B. (2018) Extreme Weather Impact on Transportation and Energy Infrastructure. Proceedings of 22nd International Scientific Conference Transport Means, October 3-5, 2018, Lithuania, ISSN 2351-7034, pp. 569-573,

[3] Crosweller, M.; Tschakert, P. (2019) Climate change and disasters: The ethics of leadership. Wiley Interdisciplinary Reviews: Climate Change. Vol. 11, No. 2, pp. 1-18, ISSN:1757-7799, DOI: 10.1002/wcc.624.

[4] Panek, J., Marek, L., Pastzo, V., Valuch, J. 2017. The Crisis Map of the Czech Republic: the nationwide deployment of and Ushahidi application for disasters. Disasters. Vol. 41, No. 4, pp. 649-671, ISSN 0361-3666, DOI: 10.1111/disa.12221.

[5] Rehak, D.; Senovsky, P.; Hromada, M.; Lovecek, T.; Novotny, P. (2018) Cascading Impact Assessment in a Critical Infrastructure System. International Journal of Critical Infrastructure Protection. Vol. 22, pp. 125-138. ISSN 18745482, DOI: 10.1016/j.ijcip.2018.06.004.

[6] European Council, Council Directive 2008/114/EC of 8 December 2008 on the identification and designation of European critical infrastructures and the assessment of the need to improve their protection, Brussels, Belgium, 2008.

[7] Zagorecki, A.; Ristvej, J.; Klupa, K. (2015) Analytics for Protecting Critical Infrastructure. COMMUNICATIONS, 1, p. 111-115. ISSN 1339-5130. 
[8] Government Regulation, Government Regulation No. 432/2010 Coll., of 30 December 2010 on Criteria for Determining Critical Infrastructure Element, Czech Republic, 2010.

[9] Valasek, J.; Kovarik, F. (2008) Crisis management in non-military crisis, module C. Czech Republic.

[10] Holla, K.; Ristvej, J.; Moricova, V.; Novak, L. (2016) Results of survey among SEVESO establishments in the Slovak Republic. Division of Chemical Health and Safety of the American Chemical Society, Vo. 7, No. 2, pp. 917. ISSN 18715532. DOI: 10.1016/j.jchas.2015.03.003

[11] Viseras, A.; Marchal, J.; Schaab, M.; Pages, J.; Eetivill, L. (2019) Wildfire Monitoring and Hotspots Detection with Aerial Robots: Measurement Campaign and First Results. Proceedings of IEEE International Symposium on Safety, Security and Rescue Robotics, September 2-4, 2019, ISBN 978-1-7281-0778-3, pp. 102-103, Germany. DOI:10.1109/SSRR.2019.8848961

[12] Singhla, G.; Bansod, B.; Mathew, L. (2018) Unmanned Aerial Vehicle Classification, Applications and challenges: A Review. Preprints 2018, 2018110601, DOI: 10.20944/preprints201811.0601.v1.

[13] Zagorecki, A.; Ristvej, J.; Comfort, L. K., Lovecek, T. (2012) Executive Dashboard Systems for Emergency Management. COMMUNICATIONS, Vol. 2, pp. 82-89. ISSN 1339-5130.

[14] Brechta, B.; Grasseova, M. 2013. Effective decision making: analysis, decision making, implementation and evaluation, BRNO: Edika. ISBN 9788026601791, Czech Republic.

[15] Ristvej, J.; Sokolova, L.; Starackova, J.; Ondrejka, R.; Lacinak, M. (2017) Expresiences with Implementation of Information Systems within Preparation to Deal with Crisis Situations in Terms of Crisis Management and Building Resilience in the Slovak Republic. Proceedings of 2017 International Carnahan Conference on Security Technology (ICCST), October 23-26, 2017, Spain. DOI: 10.1109/CCST.2017.8167821

[16] Vichova, K.; Hromada, M.; Valasek, J.; Paulus, F. (2020) Integrated Rescue System and the Use of Unmanned Aerial Vehicle not only for the Population Protection. Proceedings of International Conference on Medical and Health Informatics (ICMHI 2020), accepted version, not published, August 14-16, 2020, Japan.

[17] The hi-tech ways Australia is fighting fires - new.com.au. Available from: https://www.news.com.au/technology/environment/the-hitech-ways-australia-is-fightingfires/video/9fb9c1958fdd79a1f6c618310e3c5f71. Accessed: 2020-06-20

[18] Paris Firefighters Used This Remote-Controlled Robot to Extinguish the Notre Dame Blaze - IEEE Spectrum. Available from: tps://spectrum.ieee.org/automaton/robotics/industrial-robots/colossus-the-firefighting-robot-thathelped-save-notre-dame. Accessed: 2020-06-20

[19] Mingsong, L.; Tugan, L. (2020) Design and Experiment of Control System of Intelligent Fire Fighting Robot. Proceedings of IEEE 4th Information Technology, Networking, Electronic and Automation Control Conference (ITNEC), p. 2570-2573, June 2020, DOI: 10.1109/ITNEC48623.2020.9084919.

[20] Novotny, G.A.; Emsenhuber, S; Klammer, P.; Pöchko, Ch., Voglsinger, F.; Kubinger, W. (2019) A Mobile Robot Platform for Search and Rescue Applications. Proceedings of 30th DAAAM International Symposium on Intelligent Manufacturing and Automation, DAAAM 2019, pp.0945-0954, B. Katalinic (Ed.), Publishedby DAAAM International, ISBN 978-3-902734-22-8, ISSN 1726-9679, Vienna, Austria. DOI: 10.2507/30th.daaam.proceedings. 131 